\title{
Statistical Analysis on Concrete Strength
}

\author{
Shan $\mathrm{Wu}$ \\ Southeast University, Nanjing, China \\ Email: huxian1206@126.com
}

\begin{abstract}
The concrete strength distribution may be treated as the normal distribution. This paper carries out the standard deviation comparison reflecting the total coefficient of variation $(\mathrm{CV})$ for the concretes of different generations with different strength, and proposes the conclusion that the assurance rate of the standard value of concrete strength in China $(95 \%)$ has been in line with the international standards.
\end{abstract}

Keywords: Concrete strength, Statistics, Year of concrete

\section{Introduction}

In order to compile the first Reinforced Concrete Structure Design Code (TJ10-74) in China, with the basic completion of the Great Proletarian Cultural Revolution, a statistic and investigation for the concrete quality was carried out in the 1970s by organizing and sending a group of statisticians to the precast factories and construction sites throughout the country. This is the first national statistical investigation for concrete strength after the founding of our country.

We collected the 28d strength data of all grades of concretes and the strength test data for factory inspection, and carried out both the statistical analysis for concrete strength and the distribution hypothesis test for the distribution. The distribution test results of concrete strength showed that, with the same statistical premises, the distribution of concrete strength can be treated as the normal distribution when its scope is not too wide. The normal distribution has two parameters, i.e., the average value and the standard deviation. Therefore, the average value and the standard deviation or the coefficient of variation of concrete strength can be used to evaluate and assess the quality management level of concrete. In the grade scope of concrete which was most widely used in the world in the 1970s, from the statistical information of many countries, the average coefficients of variation are mainly from $13 \%$ to $15 \%$. In the Suggestions on Test Results Assessment for Concrete Strength (revision of ACT214-65) published in 1976 in America, it is noted that the concrete is a low-grade concrete (see Table 1) if its standard deviation reflecting the total variation is higher than $700 \mathrm{PSi}(\approx 4.92 \mathrm{~N} / \mathrm{mm} 2)$. In other words, the units producing the concrete have a very low production management level. In the national standards of the Soviet Union Inspection and Assessment for the Homogeneity and Strength of Concrete (ГОCT 18105-72), it is noted that the homogeneity of concrete is considered to have failed the test if the batch coefficient of variation of concrete strength is higher than $16 \%$ or the total coefficient of variation of concrete strength is higher than $20 \%$.

Table 1. Test Results Assessment for Concrete Strength (revision of ACT214-65)

\begin{tabular}{lccccc}
\hline \multicolumn{1}{c}{ Quality level of concrete } & A & B & C & D & E \\
\hline standard deviation reflecting the total & & $400(2.81)$ & $500(3.52)$ & $600(4.22)$ & \\
variation $\odot$ PSi(N/mm2) & $<400(2.81)$ & $\sim$ & $\sim$ & $\sim$ & $>700(4.92)$ \\
& & $500(3.52)$ & $600(4.22)$ & $700(4.92)$ & \\
\hline
\end{tabular}

After the reform and open policy, in order to find out the concrete quality level in our country and provide basis for the establishment of the Inspection and Assessment Standard for Concrete Strength (GBJ107-87), the Code for Design of Concrete Structures and the Standard for Quality Control of Concrete (GB50164-92), under the auspices of the formal Construction Bureau of the National Construction Committee and the Code Office of Scientific and Technology Board of the General Administration of Construction, we organized the relevant departments and carried out a statistical 
investigation for the concrete strength from 10 provinces since 1979. By the second quarter of 1980,916 statistics of concrete strength had been collected (the statistics period of each statistic is one quarter), about more than 60 thousands sets of cubic compression strength data of concrete samples had been obtained, and 77 precast plants and 104 construction units were involved in the investigation ${ }^{[1]}$. The parameters of the national concrete strength in accordance with the mark number are shown in Table 2.

Table 2. 1979-1980 national concrete strength statistical result

\begin{tabular}{cccccccc}
\hline $\mathrm{Rb}$ & & $\mathrm{n}$ & $\bar{R}(\mathrm{Mpa})$ & $\sigma_{1}(\mathrm{Mpa})$ & $\mathrm{C}_{\mathrm{v} 1}(\%)$ & $\sigma_{2}(\mathrm{Mpa})$ & $\mathrm{C}_{\mathrm{v} 2}(\%)$ \\
\hline \multirow{4}{*}{ In-factory } & 150 & 1716 & 19.3 & 3.69 & 19.1 & 3.87 & 20.1 \\
& 200 & 9377 & 26.7 & 4.43 & 16.6 & 5.18 & 19.4 \\
& 300 & 31569 & 35.7 & 4.57 & 12.8 & 5.32 & 14.9 \\
& 400 & 4353 & 43.3 & 4.31 & 10.0 & 4.48 & 10.4 \\
\hline \multirow{5}{*}{ On-site } & 100 & 415 & 14.6 & 3.40 & 23.3 & 3.44 & 23.6 \\
& 150 & 5891 & 19.4 & 4.28 & 22.1 & 4.54 & 23.4 \\
& 200 & 12363 & 25.2 & 4.95 & 19.6 & 5.40 & 21.4 \\
& 300 & 2663 & 34.5 & 5.52 & 16.0 & 5.93 & 17.2 \\
& 400 & 337 & 45.1 & 5.05 & 11.2 & 5.49 & 12.2 \\
\hline
\end{tabular}

Notes: $\mathrm{Rb}$ - design mark number for concrete;

$\mathrm{n}$ - the total set number of concrete samples in the statistics;

$\bar{R}$ - the weighted mean value of the concrete samples strength throughout the country (N/mm2);

$\sigma_{1}$ - the national weighted mean value of the strength standard deviation of the concrete samples with the same mark number and age and the similar mixture ratio and process conditions in all units $(\mathrm{N} / \mathrm{mm} 2)$;

$\mathrm{C}_{\mathrm{vl}}-$ the national weighted mean value of the coefficient of variation $\left(\mathrm{Cvl}=\sigma_{1} / \times 100 \%\right)$ corresponding to $\sigma_{1}$ $(\mathrm{N} / \mathrm{mm} 2)$;

$\sigma_{2}$ - the national weighted mean value of the strength standard deviation of the concrete samples with the same mark number in all units $(\mathrm{N} / \mathrm{mm} 2)$;

$\mathrm{C}_{\mathrm{v} 2}$ - the national weighted mean value of the coefficient of variation $\left(\mathrm{Cv} 2=\sigma_{2} / \times 100 \%\right)$ corresponding to $\sigma_{2}$ $(\mathrm{N} / \mathrm{mm} 2)$.

The statistical results show that the national mean value of the coefficient of strength variation of concretes from $100 \#$ to $400 \#$ is $16.5 \%$, where, the mean value of coefficient of variation of concrete strength is $13.8 \%$ because of the better production management in the precast factory, and it is $19.6 \%$ at the construction site. The mean value of coefficient of variation has been in close to the lower-middle-level in some advanced countries.

Table 3. Comparison of statistical parameters of concrete strength in 1970 and 1980

\begin{tabular}{|c|c|c|c|c|c|c|c|c|c|c|c|c|c|c|c|c|c|}
\hline \multirow[t]{2}{*}{ category } & \multirow[t]{2}{*}{ Year } & \multirow{2}{*}{\begin{tabular}{|c|}
$\begin{array}{c}\text { Strength } \\
\text { grading }\end{array}$ \\
Index \\
$\mathrm{N} / \mathrm{mm}^{2}$ \\
\end{tabular}} & \multicolumn{3}{|c|}{ No. 100} & \multicolumn{3}{|c|}{ No.150 } & \multicolumn{3}{|c|}{ No.200 } & \multicolumn{3}{|c|}{ No.300 } & \multicolumn{3}{|c|}{ No.400 } \\
\hline & & & $\mathrm{n}$ & $\begin{array}{l}\bar{R} / \\
\mathrm{Rb}\end{array}$ & $\sigma$ & $\mathrm{n}$ & $\begin{array}{l}\bar{R} / \\
\mathrm{Rb}\end{array}$ & $\sigma$ & $\mathrm{n}$ & $\begin{array}{l}\bar{R} / \\
\mathrm{Rb}\end{array}$ & $\sigma$ & $\mathrm{n}$ & $\begin{array}{l}\bar{R} / \\
\mathrm{Rb}\end{array}$ & $\sigma$ & $\mathrm{n}$ & $\begin{array}{l}\bar{R} / \\
\mathrm{Rb}\end{array}$ & $\sigma$ \\
\hline \multirow{2}{*}{$\begin{array}{c}\text { In-facto } \\
\text { ry }\end{array}$} & \multicolumn{2}{|c|}{$1970 \sim 1971$} & & & & & & & & 1.28 & 5.03 & & 1.11 & 0.00 & & 1.02 & 5.44 \\
\hline & \multicolumn{2}{|c|}{$1979 \sim 1980$} & & & & 1716 & 1.26 & 3.52 & 9377 & 1.38 & 4.38 & 31569 & 1.22 & 4.57 & 4353 & 1.10 & 4.43 \\
\hline \multirow[t]{2}{*}{ On-site } & \multicolumn{2}{|c|}{$1970 \sim 1971$} & & & & & 1.15 & 4.42 & & 1.14 & 5.69 & & 1.03 & 6.98 & & 1.01 & 6.54 \\
\hline & \multicolumn{2}{|c|}{$\begin{array}{l}1979 \sim 1980 \\
\end{array}$} & 415 & 1.33 & 2.96 & 5891 & 1.26 & 4.23 & 12363 & 1.26 & 4.84 & 2663 & 1.17 & 5.29 & 337 & 1.16 & 5.26 \\
\hline
\end{tabular}

The above statistics reveal that the production management level of concrete is relatively backward at that time in our country, especially for the construction system. But compared with the national statistics from 1970 to 1971 (see Table 3), attention should be paid to the constant improvement of the concrete quality management work. From the two statistics of which the interval has approached ten years, the development of all departments is unbalanced in the work of improving concrete quality management, and 
the management work of quite a few departments is still staying at a low level. Therefore, it has great potential capacity to improve management for ensuring the engineering quality and increasing the economic benefits.

\section{Major Changes of Statistical Investigation Principles and Concrete Compression Strength Grade}

\subsection{Statistical Investigation Principles}

There are mainly two principles in the statistical investigations. Firstly, the strength data must be true. Secondly, the sources of strength data must be representative. Only in this way, the statistics can really reflect the concrete quality management level in our country.

By now, three national statistical investigations for concrete strength have been carried out. The data veracity of the first two statistical investigations is no problem. The data for the second statistical investigation is the most representative one (include the completeness of regions and concrete strength grades). In the third statistical investigation, to mainly avoid the untrue data in the investigation report, the representative units, the friends good in their work and the staff participated in the editing of inspection and assessment standards throughout the country were invited to collect the strength data of all grades of concrete according to the uniform regulations in their regions, and more than 36 thousands sets of representative strength data were collected from six areas and four direct municipalities in China [1].

\subsection{Major Changes of Concrete Compression Strength Grade}

Replacement of Design Mark Number for Concrete

\subsubsection{Reasons for Replacement}

As everyone knows, the grade of concrete based on the cubic compressive strength was known as the concrete design mark number in the past in China. It was a unit of measurement for the physical and mechanical properties of concrete and a main technical index which was commonly used to assess the concrete quality. In addition, it was a basic parameter to reflect the concrete engineering quality [2]. We give below all the regulations related to the past codes elicited:

In the reinforced concrete structure design code (TJ10-74) published in 1974, it is noted that the concrete mark is refer to the compression strength of the cube sample $(20 \mathrm{x} 20 \mathrm{x} 20 \mathrm{~cm})$ measured with the standard test method, and which has been made and cured in accordance with the standard method for 28 days. It is clearly identified in the explanation that the strength has an assurance rate not less than $85 \%$ for the concrete mark number [3].

In the code for construction and acceptance of reinforced concrete engineering (GBJ204-83) published in 1983, the standard cube sample for concrete mark with dimension 20x20x20cm was replaced with the standard cube sample for concrete mark with dimension $15 \times 15 \times 15 \mathrm{~cm}$, but no specific statistical definition was prepared for the standard value of concrete mark number.

In the Unified Standard for Reliability Design of Building Structures (GB 50068-2001) published in 2001, it is noted that the standard value of strength of materials shall be determined by the 0.05 quantile of probability distribution, in other words, the standard value of strength of materials shall has an assurance rate not less than $95 \%$ [4].

In the Grading Standard for Concrete Compression Strength (ISO3893) published by the International Standardization Organization (ISO) in 1977, the concrete 28-day compression strength is suggested to be used for the establishment of grading system, the cylinder $(\varnothing 150 \times 300 \mathrm{~mm})$ or the cube $(150 \times 150 \times 150 \mathrm{~mm})$ is suggested to be used as the standard sample, and the curing of standard samples shall be carried out in accordance with the international standard ISO2736. In addition, it is the definition for concrete characteristic strength that the probability to be less than the strength shall be not higher than $5 \%$ in all the measured values of concrete strength (i.e., 0.05 quantile). In the newly revised standards and codes of countries after 1977, the principles for concrete strength grading are in accordance with the relevant provisions of the international standard. The Reinforced Concrete Structure Design Code (TQL33411) published by the East Germany in 1980 and the Concrete \& Reinforced Concrete Structure Design Code (CHNII2.03.01-84) published by the Soviet Union in 1984 are two good examples. 
In preparation of codes and standards, considering the problem of unified codes, and combined with the Grading Standard for Concrete Compression Strength (ISO3893) published by the International Standardization Organization (ISO) in 1977 and the revision trend of the relevant codes in some countries, a conclusion was drawn that the grading of concrete compression strength shall be in line with the international standard after several times discussions and deliberations. Therefore, the revision of standard was carried out.

\subsubsection{Revisions}

(1) The cube $200 \mathrm{~mm}$ on each edge was replaced with the cube $150 \mathrm{~mm}$ on each edge as the standard concrete sample.

(2) The concrete mark number was replaced with the concrete strength grade as the grade name of concrete strength.

(3) In the former Reinforced Concrete Structure Design Code (TJ10-74), the standard value of concrete strength grade is equal to the average value of general strength distribution minus one time of standard deviation (the assurance rate is about $85 \%$ ). Now, the standard value of concrete strength grade is equal to the average value of general strength distribution minus 1.645 times of standard deviation (the assurance rate is about $95 \%$ ).

In addition, according to provisions of the international Design of Structures -General Symbol Units of Measurement and Basic Terms (GBJ83-85), The formerly used illegal measurement units shall be replaced with the new legal measurement units for the concrete strength and its standard deviation value, and the conversion relationship between them shall be expressed as $1 \mathrm{kgf} / \mathrm{cm}^{2} \approx 0.1 \mathrm{~N} / \mathrm{mm}^{2}$ or $1 \mathrm{kgf} / \mathrm{cm}^{2}=0.0981 \mathrm{~N} / \mathrm{mm}^{2}$ (legal measurement units).

\subsection{Relationship of Concrete Mark Number and Concrete Strength Grade}

There is a quantitative relationship on the strength value between the above revised strength grade of concrete and the concrete mark number adopted in the former Reinforced Concrete Structure Design Code (TJ10-74), as shown in Table 4.

Table 4. Relationship between concrete grade and strength grade

\begin{tabular}{ccccc}
\hline $\begin{array}{c}\text { fcu.k } \\
\left(\mathrm{N} / \mathrm{mm}^{2}\right)\end{array}$ & $\delta$ & $(1-\delta) \times 0.95 /(1-1.645 \delta)$ & $\begin{array}{c}\mathrm{Rb} 20 \\
\left(\mathrm{~N} / \mathrm{mm}^{2}\right)\end{array}$ & $\begin{array}{c}\text { Rb20-- fcu.k } \\
\left(\mathrm{N} / \mathrm{mm}^{2}\right)\end{array}$ \\
\hline 10.0 & 0.24 & 0.1930 & 11.9 & 1.9 \\
15.0 & 0.21 & 1.1466 & 17.2 & 2.2 \\
20.0 & 0.18 & 1.1067 & 22.1 & 2.1 \\
25.0 & 0.16 & 1.0831 & 27.1 & 2.1 \\
30.0 & 0.14 & 1.0615 & 31.6 & 1.8 \\
35.0 & 0.13 & 1.0513 & 36.8 & 1.8 \\
40.0 & 0.12 & 1.0416 & 41.7 & 1.7 \\
45.0 & 0.12 & 1.0416 & 46.9 & 1.9 \\
50.0 & 0.11 & 1.0323 & 51.6 & 1.6 \\
60.0 & 0.10 & 1.0233 & 61.4 & 1.4 \\
\hline
\end{tabular}

Notes: Rb20 - the value of concrete mark is $\mathrm{R}(1-\delta)$

fcu.k - the standard value of concrete cube compression strength, and its value is $\mu$ fcu (1-1.645 $\delta$ );

0.95 - the reduction coefficient for the sample strength between the cube $150 \mathrm{~mm}$ on each edge and the cube $200 \mathrm{~mm}$ on each edge.

$\delta$ - the coefficient of variation of concrete sample strength, and its value is determined in accordance with the national concrete strength statistics from 1979 to 1980.

From Table 4 and Figure 1, for a batch of concrete with the same quality, the differences are $2.0 \mathrm{~N} / \mathrm{mm}{ }^{2}$ when the design mark number and strength grade are calculated in accordance with the legal measurement units, and the differences are about $20 \mathrm{kgf} / \mathrm{cm}^{2}$ if the metric measurement units are used to calculate them. In other words, the strength value of number 200 concrete is equal to the strength value of $\mathrm{C} 18$ concrete. But for the two concretes, the assurance rates of standard strength values are different. In other words, C20 
concrete's role in structure is equal to the role of $220 \mathrm{kgf} / \mathrm{cm}^{2}$ - concrete. Therefore, under the same structural reliability of the new and old codes, the design strength value of $\mathrm{C} 20$ concrete in the Code for Design of Concrete Structure (GBJ10-89) to be revised at that time is higher than the design strength value of number 200 concrete in the Reinforced.

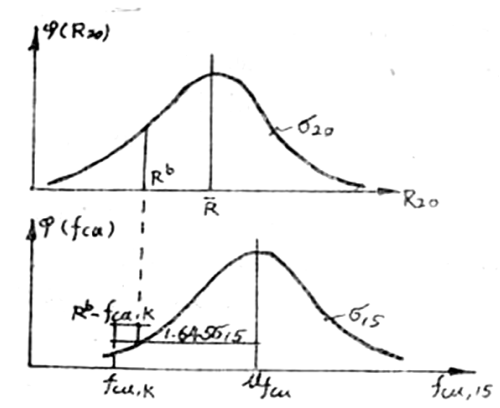

Figure 1. Concrete Structure Design Code (TJ10-74).

\section{Concrete Strength Statistics in 2008}

The interval between the third national statistical investigation for concrete strength and the first one has approached 28 years. Today the concrete technology has a large development as follows: (1) the concrete composition has developed from the four components (cement, water, sand and gravel) to the six components (cement, water, sand, gravel, admixture and mixture); (2) the concrete production technology has developed from the pre-cast concrete to the premixed concrete, and the concrete engineering is completed only through three links factory production, mechanical haulage and pumping construction; (3) the concrete mixture has developed from rigid concrete, semi-rigid concrete and plastic concrete to the fluidity concrete and the high fluidity concrete; (4) the concrete strength mark number (Rb) has been replaced with the concrete strength grade, and the highest concrete grade has been increased from C60 to C80 in the code and C100 in the practical engineering application; (5) the assurance rate of the standard value of concrete strength $(\mathrm{fcu}, \mathrm{k})$ has reached $95 \%$ in line with the international standard ISO3893.

Table 5. Statistics and calculation results of national concrete strength in 2008

\begin{tabular}{ccccccccc}
\hline $\begin{array}{c}\text { Strength } \\
\text { grading }\end{array}$ & $\mathrm{n}$ & $\begin{array}{c}\mathrm{mf} \\
(\mathrm{MPa})\end{array}$ & $\begin{array}{c}\sigma \\
(\mathrm{MPa})\end{array}$ & $\begin{array}{c}\delta \\
(\%)\end{array}$ & $\begin{array}{c}\mathrm{mf} / \\
\text { fcu.k }\end{array}$ & $\begin{array}{c}\mathrm{m} 1= \\
\mathrm{fcu} . \mathrm{k}+1.645 \sigma(\mathrm{MPa}) 1.1(\mathrm{fcu} . \mathrm{k}+1.645 \sigma)(\mathrm{MPa}) \mathrm{fcu} . \mathrm{k}+2 \sigma(\mathrm{MPa})\end{array}$ \\
\hline C15 & 1611 & 20.9 & 2.80 & 13.40 & 1.39 & 19.6 & 21.6 & 20.6 \\
C20 & 3586 & 27.4 & 3.00 & 10.95 & 1.37 & 24.9 & 33.8 & 26.0 \\
C25 & 5749 & 33.5 & 3.50 & 10.45 & 1.34 & 30.8 & 39.2 & 32.0 \\
C30 & 12508 & 39.4 & 3.40 & 8.63 & 1.31 & 35.6 & 44.7 & 46.8 \\
C35 & 4324 & 44.6 & 3.40 & 7.62 & 1.27 & 40.6 & 50.5 & 47.8 \\
C40 & 4454 & 49.9 & 3.60 & 7.21 & 1.25 & 45.9 & 56.2 & 52.4 \\
C45 & 945 & 55.4 & 3.70 & 6.68 & 1.23 & 51.1 & 66.7 & 58.1 \\
C50 & 2586 & 59.5 & 4.07 & 6.84 & 1.19 & 56.7 & 74.4 & 61.8 \\
C55 & 85 & 65.6 & 3.40 & 5.18 & 1.19 & 60.6 & 97.7 & 69.3 \\
C60 & 554 & 71.5 & 4.64 & 6.49 & 1.19 & 67.6 & 117.5 & 90.8 \\
C80 & 385 & 94.9 & 5.38 & 5.67 & 1.19 & 88.9 & 106.9 & 108.3 \\
C100 & 205 & 117.8 & 4.17 & 3.54 & 1.18 & 106.9 & \\
\hline
\end{tabular}

Notes: $\mathrm{n}$ - set number, $\mathrm{mf}$ - average strength, $\sigma$-standard deviation, $\delta$-coefficient of variation, and $\mathrm{m} 1, \mathrm{~m} 2$ and m3 separately represent the batch strength of concrete to meet different requirements.

In order to revise the inspection and assessment standard for concrete strength (GBJ107-87), the code for design of concrete structures (GB50010-2002) and the structure reliability design criteria, the third statistical investigation for concrete strength was implemented in 2008. The cities involved in the third 
statistical investigation include Beijing, Shanghai, Tianjin, Chongqing, Shenzhen (Guangdong Province), Guangzhou (Guangdong Province), Taiyuan (Shanxi Province), Wuhan (Hubei Province), Liuzhou (Guangxi Province), Ningbo (Zhejiang Province), Shenyang (Liaoning Province) and Yinchuan (Ningxia Hui Autonomous Region). There are more than 36 thousands sets of data, and the statistical results are shown in Table 5. The strength data are mainly the factory inspection results of the concrete batching plants with 12 grades from $\mathrm{C} 15$ to $\mathrm{C} 100$, and the average strength value (mf) and the standard deviation $(\sigma)$ of all grades of concretes are the weighted mean value in Table 5.

The statistical results show that:

$(1)$ When the strength grade is higher than $\mathrm{C} 25$, the standard deviation of concrete $(\sigma)$ changed little, and the coefficient of variation $(\delta)$ changed greatly;

(2) The ratio between the average strength value $(\mathrm{mf})$ and the standard strength value $(\mathrm{fcu}, \mathrm{k})$ is decreased with the improvement of strength grade. But when the strength grade is from C50 to C100, the ratio changed little;

(3) From comparison of the three possible batch strength $(\mathrm{m} 1, \mathrm{~m} 2$ and $\mathrm{m} 3)$ and the practical average strength of all grades of concretes $(\mathrm{mf}), \mathrm{m} 2$ is close to the actual statistical results. Considering the unpredictable factors in construction, to ensure that the concrete strength still can meet the design requirements, it is suggested that the considerable surplus should be prepared for the batch strength of concrete $(\mathrm{fcu}, 0)$.

\subsection{Statistical Results Comparison for Concrete Strength of Different Generations}

Before 1987, the hierarchical name of concrete compression strength is known as the concrete standards in China, which is represented by the letters " $\mathrm{Rb}$ ", and the average strength is represented by $\mathbf{R}$. After implementation of GBJ107-87 standards, the rating of concrete strength began to be in line with the national standards ISO3893. The specific transition method from "mark number" to "strength grade" is provided in standards and codes in the late 1980s, and it is not provided in the design and construction codes after 1999. The symbol in the parentheses represents GBJ107 — 87 in Table 6.

Table 6. Comparison of statistical results of concrete strength in different ages

\begin{tabular}{|c|c|c|c|c|c|c|c|c|c|c|c|c|c|c|c|}
\hline \multirow{2}{*}{ year grading } & \multicolumn{3}{|c|}{$\begin{array}{l}150 \# \\
(\mathrm{C} 15)\end{array}$} & \multicolumn{3}{|c|}{$\begin{array}{l}200 \# \\
(\mathrm{C} 20)\end{array}$} & \multicolumn{3}{|c|}{$\begin{array}{l}300 \# \\
\text { (C30) }\end{array}$} & \multicolumn{3}{|c|}{$\begin{array}{l}400 \# \\
(\mathrm{C} 40)\end{array}$} & \multirow[t]{2}{*}{ category } & \multirow[t]{2}{*}{ note } & \multirow{2}{*}{$\begin{array}{l}\text { coefficient of } \\
\text { variation } \delta \\
(\%)\end{array}$} \\
\hline & $\frac{\bar{R}}{R^{b}}$ & $\begin{array}{c}\sigma \\
(\mathrm{MPa})\end{array}$ & $\begin{array}{c}\delta \\
(\%)\end{array}$ & $\frac{\bar{R}}{R^{b}}$ & $\begin{array}{c}\sigma \\
(\mathrm{MPa})\end{array}$ & $\begin{array}{c}\delta \\
(\%)\end{array}$ & $\frac{\bar{R}}{R^{b}}$ & $\begin{array}{c}\sigma \\
(\mathrm{MPa})\end{array}$ & $\begin{array}{c}\delta \\
(\%)\end{array}$ & $\frac{\bar{R}}{R^{b}}$ & $\begin{array}{c}\sigma \\
(\mathrm{MPa})\end{array}$ & $\begin{array}{c}\delta \\
(\%)\end{array}$ & & & \\
\hline $1970-1971$ & - & - & - & 1.28 & 5.03 & 19.65 & 1.11 & 5.38 & 16.16 & 1.02 & 5.44 & 13.33 & In & according & 16.8 \\
\hline $1979-1980$ & 1.26 & 3.52 & 18.62 & 1.38 & 4.38 & 15.87 & 1.22 & 4.57 & 12.49 & 1.10 & 4.43 & 10.07 & -factory & $\begin{array}{l}\text { to concrete } \\
\text { label }\end{array}$ & 14.26 \\
\hline $2005-2008$ & 1.39 & 2.8 & 13.43 & 1.37 & 3.00 & 10.95 & 1.31 & 3.4 & 8.65 & 1.25 & 3.6 & 7.20 & On-site & $\begin{array}{l}\text { according } \\
\text { to strength } \\
\text { grade }\end{array}$ & 10.06 \\
\hline
\end{tabular}

Note: the value in the table is non weighted average

The statistical results of the three investigations (Table 6) show that, with the development of concrete technology and the constant improvement of quality management level, the ratio between the average concrete strength $(\mathrm{mf})$ and the standard value $(\mathrm{fcu}, \mathrm{k})$ is improving, and the standard deviation of strength $(\sigma)$ reflecting the quality management level of concrete is decreasing.

\subsection{Statistical Results Comparison of Concrete Strength for Delivery Inspection and Concrete Strength for Factory Inspection}

Because the data for delivery inspection are difficult to collect, the strength data collected throughout the country are mainly the results for factory inspection. Therefore, the C30 grade of concrete is used for the test, which is most widely used in constructions. Its strength for factory inspection and delivery inspection 
are shown in Table 7 , Table 8 and Table 9.

Table 7. C30 (standard condition for factory)

\begin{tabular}{cccccc}
\hline $\mathrm{n}$ & $\mathrm{m}_{\mathrm{f}}$ & $\mathrm{f}_{\max }$ & $\mathrm{f}_{\min }$ & $\mathrm{s}_{\mathrm{f}}$ & date \\
\hline 45 & 39.5 & 48.1 & 35.6 & 3.00 & 2006.3 .16 \\
39 & 39.0 & 48.9 & 36.1 & 3.20 & $\sim$ \\
factory 84 & average 39.3 & 48.5 & & 3.28 & 2006.7 .6 \\
\hline
\end{tabular}

Table 8. C30 (standard condition for delivery)

\begin{tabular}{ccccccc}
\hline $\mathrm{n}$ & $\mathrm{m}_{\mathrm{f}}$ & $\begin{array}{c}\mathrm{f}_{\max } \\
\mathrm{MPa}\end{array}$ & $\begin{array}{c}\mathrm{f}_{\min } \\
\mathrm{MPa}\end{array}$ & $\begin{array}{c}\mathrm{s}_{\mathrm{f}} \\
\mathrm{MPa}\end{array}$ & $\begin{array}{c}\delta \\
(\%)\end{array}$ & date \\
\hline 148 & 38.3 & 48.2 & 32.2 & 3.51 & 9.16 & \\
67 & 33.5 & 52.4 & 34.5 & 3.88 & 11.58 & $06.1 \sim 06.2$. \\
138 & 40.8 & 51.2 & - & 3.63 & 8.90 & $06.3 \sim 06.4$ \\
124 & 41.6 & 51.6 & 34.6 & 3.99 & 9.59 & $06.4 \sim 06.5$ \\
110 & 39.4 & 49.5 & 35.1 & 3.48 & 8.83 & $06.5 \sim 06.6$ \\
127 & 39.1 & 49.5 & 34.5 & 3.47 & 8.87 & $06.6 \sim 06.7$ \\
delivery 714 & average 39.2 & 50.2 & - & 3.64 & & - \\
\hline
\end{tabular}

Table 9. Comparison

\begin{tabular}{ccccc}
\hline $\mathrm{n}$ & $\mathrm{m}_{\mathrm{f}}(\mathrm{MPa})$ & $\mathrm{f}_{\max }(\mathrm{MPa})$ & $\mathrm{s}_{\mathrm{f}}(\mathrm{MPa})$ & $\delta \%$ \\
\hline delivery 714 & average 39.2 & 50.2 & 3.64 & 9.29 \\
factory 84 & average 39.3 & 48.5 & 3.28 & 8.35 \\
\hline
\end{tabular}

From the weighted mean value in Table 7 , Table 8 and Table 9 , the average strength value (mf) of the strengthen for factory inspection and the strength for delivery inspection is basically consistent with the standard deviation (sf).

\subsection{Statistical Information in the Construction Site}

The statistical results of C25 and C35 grade of concrete strength at the construction sites in Table 10 and Table 11 show that, their weighted mean value of strength (mf) and the standard deviation (sf) are basically consistent with the national statistical results, and their average strength are higher than the national statistical results.

Table 10. C25

\begin{tabular}{ccccccc}
\hline $\mathrm{n}$ & $\mathrm{m}_{\mathrm{f}}$ & $\mathrm{f}_{\max }$ & $\mathrm{f}_{\min }$ & $\mathrm{s}_{\mathrm{f}}$ & $\delta(\%)$ & date \\
\hline 50 & 31.9 & 41.5 & 26.4 & 3.67 & 11.5 & $05.12 \sim 06.1$ \\
17 & 32.5 & 38.5 & 27.2 & 3.52 & 10.83 & $06.1 \sim 06.2$. \\
6 & 33.1 & 40.2 & 29.6 & 3.79 & 11.45 & $06.2 \sim 06.3$ \\
107 & 33.4 & 46.1 & 28.9 & 3.44 & 10.30 & $06.3 \sim 06.4$ \\
273 & 34.2 & 43.4 & 28.4 & 3.16 & 9.24 & $06.4 \sim 06.5$ \\
348 & 34.3 & 42.5 & 28.8 & 3.11 & 9.07 & $06.5 \sim 06.6$ \\
181 & 34.6 & 41.2 & 29.2 & 3.15 & 9.10 & $06.6 \sim 06.7$ \\
982 & average 34.1 & 42.8 & - & 3.21 & 9.41 & - \\
\hline
\end{tabular}


Table 11. C35

\begin{tabular}{ccccccc}
\hline $\mathrm{n}$ & $\mathrm{m}_{\mathrm{f}}$ & $\mathrm{f}_{\max }$ & $\mathrm{f}_{\min }$ & $\mathrm{s}_{\mathrm{f}}$ & $\delta \%)$ & date \\
\hline 32 & 43.0 & 50.5 & 37.8 & 3.11 & 7.23 & $05.12 \sim 06.1$ \\
78 & 43.3 & 50.0 & 40.4 & 3.22 & 7.44 & $06.1 \sim 06.2$. \\
99 & 47.5 & 60.1 & 40.1 & 3.95 & 8.32 & $06.3 \sim 06.4$ \\
294 & 46.5 & 57.9 & 40.3 & 3.57 & 7.68 & $06.4 \sim 06.5$ \\
294 & 46.2 & 57.8 & 39.7 & 3.70 & 8.01 & $06.5 \sim 06.6$ \\
225 & 47.2 & 57.8 & 40.7 & 4.00 & 8.47 & $06.6 \sim 06.7$ \\
1022 & average 46.3 & 57.2 & - & 3.70 & 7.99 & - \\
\hline
\end{tabular}

Table 12. Comparison of standard curing strength and curing condition of same condition

\begin{tabular}{|c|c|c|c|c|c|c|c|c|c|c|c|c|}
\hline \multicolumn{6}{|c|}{ Same curing condition } & name & \multicolumn{6}{|c|}{ Standard curing } \\
\hline$\delta \%)$ & grading & $\mathrm{n}$ & fmin & $\mathrm{mf}$ & sf & - & grading & $\mathrm{n}$ & fmin & $\mathrm{mf}$ & sf & $\delta \%)$ \\
\hline 10.7 & $\mathrm{C} 20$ & 19 & 20.8 & 25.6 & 2.22 & project1 & $\mathrm{C} 20$ & 17 & 17.8 & 23.4 & 2.98 & 12.74 \\
\hline 8.4 & & 34 & 19.4 & 25.4 & 2.13 & project2 & & 32 & 9.10 & 23.6 & 3.76 & 15.93 \\
\hline 14.8 & $\mathrm{C} 25$ & 38 & 26.7 & 33.2 & 4.91 & project3 & $\mathrm{C} 25$ & 39 & 15.7 & 30.6 & 4.08 & 13.33 \\
\hline 5.7 & C30 & 35 & 36.0 & 38.2 & 2.06 & project 4 & C30 & 18 & 32.0 & 37.5 & 3.60 & 9.60 \\
\hline 8.4 & C35 & 55 & 34.0 & 36.2 & 3.06 & project5 & C35 & 42 & 25.8 & 35.4 & 3.75 & 10.59 \\
\hline & & & & & & erage & & & & & & 12.44 \\
\hline
\end{tabular}

Table 13. Concrete strength test result

\begin{tabular}{|c|c|c|c|c|c|c|c|c|}
\hline \multirow{3}{*}{ grading } & \multirow{3}{*}{ number } & \multirow{3}{*}{$\mathrm{m}_{\mathrm{f}}$} & \multirow{3}{*}{$\mathrm{f}_{\min }$} & \multirow{3}{*}{$\mathrm{s}_{\mathrm{f}}$} & \multirow{2}{*}{\multicolumn{2}{|c|}{$\begin{array}{c}\text { GBJ107-87 } \\
\text { failure number }\end{array}$}} & \multirow{2}{*}{\multicolumn{2}{|c|}{$\begin{array}{l}\text { GB50107-2010 } \\
\text { failure number }\end{array}$}} \\
\hline & & & & & & & & \\
\hline & & & & & statistical & nonstatistical & statistical & nonstatistical \\
\hline $\mathrm{C} 10$ & 13 & $14.4-19.1$ & $12.1-15.3$ & $1.21-2.82$ & 0 & 0 & 0 & 0 \\
\hline $\mathrm{C} 15$ & 22 & $18.8-23.8$ & $14.1-20.6$ & $0.80-5.95$ & 0 & 0 & 0 & 0 \\
\hline $\mathrm{C} 20$ & 22 & $24.8-35.3$ & $21.0-33.8$ & $1.02-4.53$ & 0 & 0 & 0 & 0 \\
\hline $\mathrm{C} 25$ & 26 & 29.0-39.0 & $23.6-32.4$ & $1.00-5.3$ & 0 & 0 & 0 & 0 \\
\hline C30 & 57 & $30.2-44.9$ & $25.4-37.8$ & $1.09-5.39$ & 9 & 1 & 16 & 1 \\
\hline C35 & 23 & $39.1-50.3$ & $36.8-45.9$ & $0.9-4.58$ & 0 & 1 & 0 & 1 \\
\hline $\mathrm{C} 40$ & 23 & $44.7-55.9$ & (29.3)40.2-52.0 & $1.25-5.98$ & 1 & 2 & 1 & 2 \\
\hline $\mathrm{C} 45$ & 7 & $53.2-62.0$ & $46.9-59.2$ & $2.65-4.59$ & 0 & 0 & 0 & 0 \\
\hline C50 & 29 & $54.9-67.1$ & $43.3-63.1$ & $1.12-6.05$ & 0 & 1 & 0 & 1 \\
\hline C55 & 4 & $61.1-73.1$ & $52.1-65.5$ & $3.62-5.28$ & 0 & 0 & 0 & 0 \\
\hline C60 & 13 & $62.7-74.5$ & $62.0-69.2$ & $1.11-5.64$ & 0 & 1 & 0 & 1 \\
\hline C65 & $1(19)$ & 78.8 & 72.4 & 5.61 & 0 & 0 & 0 & 0 \\
\hline $\mathrm{C} 70$ & $1(19)$ & 83.5 & 74.6 & 5.09 & 0 & 0 & 0 & 0 \\
\hline C80 & 8 & $94.1-106.2$ & $68.4-94.6$ & $1.8-13.21$ & 0 & 0 & 0 & 0 \\
\hline $\mathrm{C} 100$ & 3 & $114.5-119.1$ & $105.2-108.8$ & $4.00-4.53$ & 0 & 0 & 0 & 0 \\
\hline total & 252 & & & & 10 & 6 & 17 & 6 \\
\hline
\end{tabular}

(1)The new programme of statistical method is stricter than the original standard;

(2)Because of the enough attention of all parts and the strict quality control, the high-strength concrete higher than C60 is regarded as qualified with both the new method and the old method.

\subsection{Statistical Results Comparison of the Strength Under the Standard Curing Conditions and the Strength Under the Same Curing Conditions for the Same Engineering}

The data in this table are obtained from the construction sites over Northwest China. The limited data are used to represent the mean value $(\mathrm{mf})$ and standard deviation $(\sigma)$ of all levels of concrete strength, which are similar to the national statistical results. At the construction site, more attention are paid to the 
concrete strength under the same curing conditions, but the standard curing conditions often are unqualified, even the minimum concrete strength value is lower than the standard value.

\subsection{Concrete Strength Test Results}

The strength test data are mainly provided by the units participating compilation of the code. The set number of each batch of strength data is from one to hundreds, the batches of data are mainly provided by all units involved, and there are 252 inspection lots with the strength grade from C10 to C100 and 9988 sets of data, where, there are 239 inspection lots from C10 to C60 with 9328 sets of data. In accordance with the new programme, 23 lots are unqualified, and the failure rate is 9.1\%. In accordance with the original programme, 16 lots are unqualified, and the failure rate is $6.4 \%$. For the unqualified lots of concrete, the average strength of inspection lots is mainly low. The statistical results are shown in Table 13.

\subsection{Test and Assessment Conditions of Concrete Strength in Some Countries}

The three statistical results show that the production management level and quality of concrete have been rising with the constant improvement of concrete technology.

\section{References}

1. China Communication Press, Mixture Ratio Design for Mixtures of Highway Engineering, 113.

2. He Yan, Influence of Implementation of the New Standard of Cement on Railway Engineering, Railway Engineering Cost

3. Management, 2001.1, 17-18.

4. Code for Construction and Acceptance of Reinforced Concrete Engineering (GBJ204-83),1984, No.4.6.3.

5. Unified Standard for Reliability Design of Building Structures (GB 50068-2001), 2002,17, No.5.0.3. 